\title{
El movimento de poblacion como estrategia de sobrevivencia de los indios en la Nueva España
}

JUAN MANUEL PEREZ ZEVALLOS*

Resumo: Um dos fatores a considerar no estudo do mundo indígena é a mobilidade de sua população. A ocupação do espaço, o deslocamento forçado de indígenas na etapa da conquista, a migração voluntária - vilas, cidades, estâncias foram utilizadas pelos índios novo-hispânicos como estratégia de sobrevivência.

Abstract: One of the aspects to be considered on the study of the indian world is the mobility of his population. The occupation of the space, the forced dislocation of indians during the conquista, the voluntary migration - small towns, cities and farms were used by new-hispanic indians as a strategy of survival.

Palavras-chave: Mobilidade populacional. Migrações indígenas. Nova Espanha.

Key words: Mobility of population. Migration of Indians. New Spain.

En la literatura sobre la historia colonial de México aparece el hecho de que la población novohispana se desplazó en grupo o individualmente. Españoles, indios, mestizos y negros fueron los protagonistas de una movilidad generalizada (Zavala, 1984; Kubler, 1942; Miranda, 1962, 1968; Martin, 1957). Sin embargo, los estudios sobre los movimientos de población han resaltado la migración española más que la indígena, mestiza o negra, como lo muestran los trabajos de Peter Boyd-Bowman $(1963,1974,1976)$ y el de Sherburne F. Cook (1970).

Professor-investigador del Centro de Investigaciones y Estudios Superiores en Atropología Social, México, DF.

Estudos Ibero-Americanos. PUCRS, v. XXV, n. 2, p. 39-60, dezembro 1999 
Muchos investigadores americanistas al estudiar a los pueblos indígenas han señalado que el desplazamiento de su población ha caracterizado también su historia. Los habitantes de la América precolombina recorrieron a menudo grandes distancias, se desplazaron por diversos medios a nuevos espacios, se asentaron en nuevos lugares y con ello, a través de milenios, modificaron su espacio, su condición económica y social. Es decir, los indígenas no han habitado siglo tras siglo un mismo lugar, sino que a menudo han cambiado de lugar de residencia. Pero, quienes han estudiado la movilidad de la población indígena colonial han tratado de explicarla como si se tratara sólo de un fenómeno migratorio (Lecoin, 1988; Percheron, 1988; Robinson, 1988). Uno desprende de estos trabajos que el movimiento de población y el fenómeno migratorio son lo mismo, aunque he de advertir que toda migración es un movimiento de población y no todo movimiento de población es una migración.

Los movimientos de población fueron significativos durante la época colonial y tuvieron diversas formas y expresiones. Los indígenas se movieron en múltiples direcciones y con diferentes intensidades. Estos desplazamientos no siempre han tenido el mismo carácter ni se han producido de la misma forma (Farriss, 1978, 1984; Robinson y McGovern, 1980; Robinson, 1981, 1988; Cook, 1976; Miranda, 1962a, 1962b, 1968; Sánchez-Albornoz, 1978, 1982a, 1982b, 1983a, 1983b, 1988), por lo que la movilidad de la población se convierte en un elemento funcional que permite entender el proceso a través del cual la sociedad indígena se integró en el sistema colonial novohispano y al mismo tiempo logró actuar y resistir de una manera creativa ante la dominación española. Desde esta perspectiva, el desplazamiento de importantes contingentes de la población india implica que la movilidad fue una estrategia que permitió la sobrevivencia del indígena y de su colectividad.

El objetivo de este trabajo es ver de qué manera impactó la movilidad de la población indígena los pueblos indios de la Nueva España.

Hemos de considerar de manera breve y general que la movilidad de la población indígena en la época prehispánica fue importante, los testimonios son abundantes. Después de la destrucción de Teotihuacan (750 d.C.) que sucumbió ante el poderío de Cholula, Xochicalco, Tula y Teotenango, sucedió en el 
altiplano de México un largo proceso de reacomodos y migraciones que implicó el repoblamiento de toda el área. A lo largo de casi dos siglos, hasta el esplendor de Tula (ca. 950 d.C.), muchos grupos mesoamericanos se desplazaron. Chichimecas, huastecos, xochimilcas, etc., recorrieron un extenso territorio y se asentaron en distintas áreas. Los grandes movimientos de población prehispánicos que se sucedieron en los siglos VIII, X-XII y XIV habían culminado con el reacomodo de los distintos grupos étnicos prehispánicos y con la caída y surgimiento de importantes centros de poder como Teotihuacan, Tula y Tenochtitlan. (López Austin, 1973; Boehm, 1986, p. 170-274; Martínez Marín, 1972, 1977; García Martínez, 1987, p. 40-54; Tira de la peregrinación; "Códice Ramírez", "Códice Xolotl", Historia Tolteca Chichimeca, Códice Aubin).

La historia de los mexicas tampoco escapa a esta movilidad. Su legitimidad y poderío se debió a la existencia de guarniciones militares, como lo sugiere Van Zantwijk ("La organización", p. 149-158), y a la fundación de colonias que sugieren el desplazamiento de importantes contingentes de guerreros hacia las zonas fronterizas y de colonos hacia pueblos que habían quedado desiertos, como ocurrió en Alahuiztlan y Oztoman,

"y llamando luego allí al embajador mayor, le mandaron que luego enviase sus embajadores a todas las provincias, conviene a saber: a Chalco, a Xuchimilco, a Cuitlahuac, a los cuatro señoríos de Colhuacan, a la provincia de la Tierra Caliente, $\mathrm{y}$ a los mazahuaques y a los cuahtlapanecas. Finalmente, a todas las ciudades sujetas a la corona real de México, para que todas fuesen a poblar aquellas dos ciudades que habían quedado desiertas, Alauistlan y Oztoman, y que ninguna ciudad bajase de veinte [vecinos]... Y cada veinte indios llevasen su principal y cabeza, para que en aquellas ciudades, puestos por sus barrios y ordenados; estuviese cada parcialidad y generación por sí, con sus mandonsillos y a quien reconociesen sujeción, para que todos acudiesen a una cabeza que iría de los señores de México, como virrey y gobernador de toda aquella gente" (Durán, Historia de las Indias, II, p. 351-355).

Lo mismo sucedía con las provincias que se aliaban para resistir la invasión mexica, sobre todo bajo el reinado de Moctezuma Xocoyotzin. ${ }^{1}$ Además, el esplendor de los mexicas requirió de importantes flujos de fuerza de trabajo para la construcción del altepetl Tenochtitlan y del desplazamiento de

\footnotetext{
"Informe del canónigo Francisco Martínez al Consejo de Indias" (1562), Archivo del Instituto de Valencia de don Juan.
} 
especialistas: artesanos, orfebres, amantecas, etc., que se ubicaron alrededor de la ciudad, así como también de quienes se encargaban del abasto y mantenimiento de la ciudad.

Al derrumbe de la Triple Alianza en 1521 principió la colonización española. A la conquista de nuevos espacios le siguió la ocupación de esos territorios cuya consecuencia inmediata fue la transformación de las sociedades indígenas. Este hecho fue evidente con la drástica caída de la población indígena, que en algunos espacios como la Huasteca y las costas de la naciente Nueva España, llegó a significar un descenso de casi un 90 por ciento de la población total para finales del siglo XVI. Situación que no impidió el desarrollo de la economía mercantil novohispana basado en el control de la fuerza de trabajo, en la introducción de los cambios tecnológicos y en la participación de los indígenas en las empresas de los españoles (Assadourian, 1989, p. 443-446).

A lo largo de la historia colonial los movimientos de población se sucedieron de manera ininterrumpida como se constata por las descripciones que existen al respecto. Sin embargo, no han merecido una especial atención de los estudiosos, ni se han analizado las implicaciones que tuvo la circulación generalizada de población.

Entre los factores que afectaron a los indígenas se pueden contar el hecho de habitar en tierras poco aptas para la agricultura y, en un plano más concreto, la práctica del repartimiento con que se normó el trabajo para la agricultura y para las minas (Gibson, 1980, p. 233-240).

La documentación colonial refleja, en un principio, que muchos de los desplazamientos fueron invariablemente forzosos. Sin embargo, los indígenas tuvieron sus razones para desplazarse por la Nueva España unas veces voluntariamente y otras no. El carácter compulsivo y forzado de la demanda de fuerza de trabajo indígena hacia los sectores productivos de los españoles "intensificó el flujo de indígenas que abandonaban sus parcelas" (Assadourian, 1985, p. 92). Aunque forzado, un porcentaje de la población indígena se trasladaba al lugar donde se le requería, y muchos que se mostraban renuentes a cumplir optaron por varios destinos, por nuevos paraderos. De esta manera, los indígenas voluntariamente se incorporaron a las principales ciudades, a la compleja red minera, a la del comercio y las fronteras, como indios 
alquilados, es decir como trabajadores temporales. Juan de Ibarra informaba al Rey, hacia finales del siglo XVI, que trabajaban en las minas "indios que de su voluntad se alquilan, que llaman naboríos y desde su niñez se han criado en ello".

El pago de la carga tributaria, las constantes retasaciones de la población, el afan de escapar al repartimiento generó un movimiento de la población indígena, motivó unas veces la huída de los naturales de su lugar de orígen y otras llevó a los indígenas a buscar trabajos remunerados allí donde las oportunidades eran mejores.

Una forma de movilidad forzada fue la venta que se hizo, en las dos primeras décadas de la vida colonial, de los indios como esclavos hacia el Caribe. Un caso que ejemplifica esto es lo que sucedió en la Huasteca. Entre 1522 y 1533 se sacaron muchos esclavos hacia las Antillas y otras partes. Los años que implicaron una movilización forzosa fueron durante el gobierno de Nuño de Guzmán, como gobernador de la Provincia de la Huasteca (15261529) y presidente de la Primera Audiencia (1529-1533), y así lo señala fray Juan de Zumárraga hacia 1528 cuando dice,

"luego que fue recibido Nuño de Guzmán a aquella gobernación, dió licencia general a todos los vecinos de aquella provincia para que pudiesen sacar della para las islas a veinte y treinta esclavos, lo cual se hizo; y como esta contratación viniese a noticia de los mercaderes y tratantes que por estas islas andan y viesen que era buena granjería, ocurrieron a la provincia de Pánuco, así por su propio interese como a llamamiento del dicho Nuño de Guzmán que envió a fletar navíos al puerto desta Nueva España para ello; y desta manera está tan rota la cosa, que aquella provincia está disipada, destruída y asolada, a causa de haber sacado della nueve o diez mil ánimas herradas por esclavos, y enviádolos a las islas".3

Esta situación duró a lo largo del siglo XVI, a pesar de la expresa prohibición del tráfico de esclavos indios. Muchas entradas de los españoles al Norte de la Nueva España estuvieron

\footnotetext{
Aunque esta observación pueda ser exagerada habría que considerar las transformaciones que ocurrieron a lo largo del siglo XVI. "Informe de los oficiales reales al Rey de manos de Juan de Ibarra su secretario" (30 abr. 1595), AGI, México, 324, 2fs.

Zavala, "Nuño de Guzmán", 413. Igual observación señala Jerónimo López en una carta enviada a la Corona entre 1530 y 1531 . "Memorial que dió por extenso Jerónimo López, conquistador de Nueva España, sobre el gobierno de aquel reino" (sin fecha), Epistolario, xv, 190-191; "Información que hizo de la villa de Santiesteban del Puerto sobre la conveniencia de enviar esclavos a las islas para cambiarlos por esclavos, yeguas y otros ganados" (9 oct. 1529), Epistolario, i, 26; Zavala, 1981.
} 
relacionadas con el captura de "piezas", 4 como fue el caso del capitán Luis de Carvajal y de la Cueva, quien entre 1576 y 1590 hizo esclavos a cientos de indios huastecos y chichimecos.

Otra forma desplazamiento en las primeras tres décadas de la Colonia, aunque no muy documentada, fue la incorporación de importantes contingentes de indígenas de distintos grupos étnicos que, encabezados por sus tlahtoque, tuvieron que acompañar a los españoles a lejanas expediciones y conquistas. Ixtlilxóchitl nos refiere que para la conquista de la Huasteca fueron más de cuarenta mil acolhuas y "algunos mexicanos" y posteriormente, en la pacificación de la misma provincia, fueron más de treinta mil tetzcocanos y mexicas, así como quinientos xochimilcas. ${ }^{6}$ Así pues, algunos contingentes importantes de población se trasladaron encabezados por uno o varios líderes si se trataba de una estrategia de los pueblos indios. En caso de no serlo, se trató de movimientos espontáneos de población, no por serlo menos importantes, "producto de situaciones de emergencia, como las producidas por las epidemias: verdaderas estampidas colectivas sin duda erráticas y tal vez temporales" o de otras situaciones.

Ante la presión colonial una de las respuestas de la población indígena fue la huída fuera de sus pueblos. ${ }^{8}$ Este abondono de sus

4 Durante la Colonia se designaba con el nombre de piezas a los indios capturados en campañas militares para ser vendidos como esclavos.

5 El virrey Villamanrique informaba al Rey que hacia 1588 "Luis había enviado a la villa de los Valles a Cristóbal de Heredia para que vendiese allí cien indios que había sacado de la tierra adentro", "Carta del marqués de Villamanrique al rey", México (4 dic. 1588), AGI, México. Del Hoyo, 1979: 131. Velázquez, 1946-48, i: 339. Toro, 19 Los judíos, 211, 372 .

" Ixtlilxochitl, "Compendio histórico", 13a rel. (Obras i: 484-486); Díaz del Castillo, Historia verdadera, cap. cxlii. "Carta de los caciques e indios naturales de Suchimilco a su majestad, alegando sus servicios desde el principio de la conquista de México, Pánuco y Xalisco, al marqués del Valle y al adelantado Alvarado, y pidiendo restitución de sus derechos y posesiones de que han sido despojados" (2 may. 1563), CDIA, xiii, 293.

7 García Martínez, Los pueblos, 261. Las epidemias ocurridas a lo largo de la época colonial, así como los desastres como los terremotos, huracanes, inundaciones, etc. fueron causantes de la movilidad de la población.

s "Que se ponga por minuta los indios que muriesen y los que se huyeron". "Poder del señor Martín de Villanueva para presentar ciertos papeles en el Consejo de Indias" (1595-1604), AGI, México, 123, ramo 1, núm. 21, f. 2r. "Y por no poder los indios como gente miserable e indefensa resistir a la fuerza de tanta codicia han desamparado cinco pueblos, como son: los Ocotlanes, Tatautalpa, Guachapa, y en los Ocotlanes se entiende que eran tres pueblos y ahora este año se fueron los indios del pueblo de Pechucalco... que es gran lástima y compasión que los indios que estaban debajo de doctrina se hayan ido a partes remotas". "Carta del teniente general de Guazacualco al Rey sobre las actividades del alcalde mayor" (1 oct. 1606), AGI, México, 125, f. 1r. Existe una copia de la carta fechada el 1 ene. 1607 en AGI, México, 126, ramo 1, núm. 2, 2 fs. 
pueblos, algunas veces voluntaria, fue forzada por las circunstancias, pero hay que tomar en cuenta que muchas de estas "ausencias" se debieron al ocultamiento de tributarios que hicieron los señores naturales, los principales y los cabildos, ${ }^{9}$ así como al desvío de los indios de repartimiento de las minas y agricultura hacia el comercio, reflejado en las constantes permutas de los indios entre barrios y entre pueblos.

A medida que se desarrollaron importantes centros como la ciudad de México, Puebla, Zacatecas, etc., los indígenas encontraron nuevos lugares a donde dirigirse y tuvieron la ocasión de optar entre varios destinos, lo que propició que la fuerza de trabajo adquiriera rasgos de ser itinerante. La creciente actividad económica de las ciudades, como México, que a mediados del siglo XVI era el centro del naciente mercado colonial y con un gran dinamismo comercial alrededor de ella atrajo a indios y no indios de distintas áreas de la Nueva España. Hacia 1554 Cervantes de Salazar señala la vida económica de la ciudad de México:

"qué multitud de tiendas y qué ordenadas, cuán provista de valiosas mercaderías, qué concurso de forasteros, compradores y vendedores" (Cervantes de Salazar, 1975, p. 35).

Las ciudades actuaron como imanes para la mano de obra indígena al grado que algunas estuvieron compuestas, principalmente, de inmigrantes. De manera forzosa unas y obligadas otras muchos indígenas de los alrededores del valle de México firmaban contratos con los españoles por diversas actividades y se quedaban a vivir en la ciudad. El virrey Luis de Velasco señalaba, de manera alarmente, a su sucesor el conde de Monterrey que las cartas de servicio disfrazaban un tipo de esclavitud en 1596,

Muchos son los ejemplos y quejas sobre el encubrimiento de tributarios por parte de los señores naturales y el cabildo, como sucedió en Tetela, "que estando tasado en sólo ciento y cincuenta tributarios por su buena industria, [de Joseph de Solís] diligencia y cuidado, halló que se habían encubierto a su majestad trecientos y más tributarios". "Joseph de Solís sobre que se le haga merced de mil pesos de renta en cada un año situados en las Real Hacienda" (1 dic. 1586), AGI, México, 134, ramo 3, núm. 32c, f. 13r. $Y$ en un mandamiento dado a Pedro Arniez de Oñate le encomendaron "averigüaréis qué fue de [la población] y si lo tienen oculta y escondida los principales y mandones y otros algunos para defraudarlos. Y si se alegare que los que faltan se han muerto y ausentado, averigüaréis el tiempo que hay, los muertos dónde se enterraron y los ausentes dónde se fueron y ausentaron y por qué causa y razón". "Información de méritos y servicios recibida en la Real Audiencia de México de pedimento de don Pedro Arniez de Oñate, factor y proveedor del puerto de Acapulco" (23 oct. 1608), AGI, México, 129, ramo 2, núm. 20b, f. 30v.-32r. 
"una gran cantidad de indios hay en este reino afligidos y que han venido a esclavonía miserablemente, tanto por su miseria y vicioso modo de vivir, tomando para este dinero adelantado a cuenta de su trabajo". ${ }^{10}$

La minería, como polo integrador del espacio económico novohispano, también jugó un papel importante en las migraciones como ocurrió luego con las haciendas del siglo XVII. Alrededor de las minas de Zultepec, Temascaltepec, Guanajuato, Tlalpuxagua, Zacualpa, Pachuca, Ozumatlan, Guautla, Tasco y Zacatecas se generó una extensa red comercial de abasto que atrajo importantes flujos de fuerza de trabajo de "indios naboríos" e "indios de repartimiento"."

Las ciudades y los centros mineros eran, pues, importantes polos de crecimiento y de atracción migratoria porque se pagaba un jornal, había condiciones mejores en el trabajo y, sobre todo, la posibilidad de escapar al control fiscal de sus pueblos. En resumen el sistema colonial impuso o alentó, conforme a sus intereses, el que los indios se desplazaran. ${ }^{12}$

Las minas proporcionaron una alternativa a los indios que huían de sus pueblos e invitaron a un desplazamiento voluntario de la fuerza de trabajo que los dueños de minas necesitaban. A los indios les dieron la oportunidad de vender su fuerza de trabajo. Los que se alquilaban por una temporada para conseguir dinero para el pago de tributos debían retornar al pueblo. En el norte, las minas alentaron un rápido crecimiento de la población que llegaba de distintas partes de la Nueva España y motivaron un fenómeno de colonización (Powell, 1977; Rabell, 1986, p. 17-34; Florescano, 1973, p. 45-51).

Los indios naboríos, la aparición de "forasteros", "fugitivos" o "vagabundos" en las minas, labores agrícolas, pueblos y ciudades ponen de manifiesto que se dió un importante movimiento de población..$^{13}$ Este fue un movimiento esencialmente

10 "Advertimiento que Luis de Velasco dejó al Conde de Monterrey" (1596), Los virreyes, ii, 101. En el AGNot de la Ciudad de México se localizan las cartas de obligación por servicio y pago de numerosos artesanos indígenas. Véase sobre todo los notarios Diego Rodríguez de León, Antonio Alonso y Juan Pérez de Rivera.

" "España y de lo que ha su merced deben procedido de azogues, sacada de la visita general que de las dichas minas se hizo por principio de 97"' (24 abr. 1598), AGI, México, leg. 24, ramo 1, núm. 7-A, 4 fs.

12 Sánchez-Albornoz, "Migración rural", 13-16; "Migraciones internas", 12-13; "Migración urbana", 277.

13 Para Yucatán encontré la presencia de importantes contingentes de "fugitivos". "Luego como llegó a esta provincia don Carlos de Luna y Arellano, nuestro gobernador, 
individual, o conformado por la suma de movimientos individuales.

Para que la articulación de los pueblos indígenas en el sistema económico colonial fuera eficiente, era necesario iniciar un proceso de reordenamiento espacial, cuya expresión fueron las congregaciones o reducciones de los pueblos indios. El reasentamiento de los pueblos no obedeció sólo a la evangelización de la población indígena, intereses nada cristianos alentaron el nuevo ordenamiento de los pueblos. Este hecho profundizó y agudizó los cambios introducidos por la conquista y la encomienda.

El desplazamiento de la población que más llamó la atención de algunos historiadores fueron las congregaciones de los pueblos indios de la Nueva España en el siglo XVI. Se han referido a las reducciones, como también se les llama, como el traslado de los habitantes de varios "caseríos dispersos" a nuevos asentamientos y como el parteaguas de las historias de los pueblos. Han caracterizado este proceso como de "ruptura radical", "drástica reorientación", "desarraigo", etc. (Cline, "Civil congregations"; Licate, Creation; Florescano, 1987, p. 157-179). Otros han señalado que es a partir de este proceso que se inicia un importante movimiento de población a gran escala ligado al abandono de las congregaciones o reducciones. Reyes (1970, p. 31-32) y Cline (1969, p. 353-354) señalan esta idea que parece confirmarse con un informe dado por los franciscanos cuando señalaron que como resultado de las congregaciones "se muere la mayor parte o se huyen llenos de aflicciones y desventuras". ${ }^{4} 4$ Sin embargo, habría que relativizar esta observación pues en un informe del virrey se señaló que,

"se ha visto por experiencia que si en alguna provincia ha sucedido que de diez poblaciones se haya errado en una o sin que hubiese hierro se tenga ahora mala satisfacción por acontecimientos de la

bajaron de la montaña algunos indios principales de los muchos cristianos fugitivos que allá hay". "Carta del provincial y definidores de San Francisco" (28 abr. 1604), AGI, México, 294, f. 1r.

"Parecer del provincial y definidor de la provincia del Santo Evangelio de la orden d "(4) "Relación del estado que tienen las haciendas de minas de la Nueva e San Francisco sobre las congregaciones" (15 may. 1603), AGI, México, 293, f. 1 r. 
salud de los indios o por haberse huído parte de la gente, en las nueve restantes hubo y hay acierto y quietud". ${ }^{15}$

La dispersión de la población indígena y el drástico descenso de la población fueron dos de las razones que sirvieron al gobierno colonial para llevar a cabo un importante programa de congregar a los indios en pueblos compactos. También fueron razones el facilitar el acceso de la fuerza de trabajo indígena voluntaria si los indios vivían cerca de las ciudades españolas y minas,

"[En] lo que toca a hacer poblaciones de indios estables y permanentes dentro y fuera de las minas... he dado más disposición a que se hagan poblaciones que sean de ayuda a las minas".

La implementación de esta política de población tuvo su propia historia. Hubieron algunas congregaciones forzadas y otras voluntarias. Las menos veces los indios estuvieron de acuerdo en mudarse, o al menos así lo señalan los testimonios hispanos. En la congregación del pueblo de Ixtlahuaca y sus sujetos "los dichos naturales con mucha conformidad empezaron a hacer sus casas y romper los solares". ${ }^{17}$ En otros casos, después de mudarse se quedaron viendo las conveniencias que les presentaba el nuevo asentamiento, como señaló el cura Hernán Vázquez Durán sobre el beneficio de San Joseph

"que es tan fértil, que aunque los naturales tienen permisión para volverse a sus antiguos puestos no lo quieren hacer, por haber acomodado en parte en donde ellos se hallan con gusto".

El trasplante de la población o relocalización física, como serían las congregaciones, significó algunas veces el traslado a mejores tierras, con lo que implicaba que los naturales reducidos quedaran complacidos, como sucedió en las congregaciones que se hicieron en Chamila y San Joseph, donde la tierra "es tan fertil, que aunque los naturales tienen permisión para volverse a sus

15 "Informe del Virrey al Rey" (1603), AGI, México, 122, ramo 1, núm. 2a, f. 2r.

16 "Que en algunas ventas de V:M: ha habido bajo este año y en otras acrecentamiento y más ley en los metales de las minas, aunque se han muerto muchos indios naboríos" (10 jun. 1599), AGI, México 24, ramo 2, num. 20, f. 2r.

17 "Proceso de la junta y congregación del pueblo de Ixtlahuaca y sus sujetos que hizo Diego de Ocampo Saavedra" (1593), AGNM, Tierras, vol. 1595, exp. 8, f. 5r.

18 "Méritos y provanzas del licenciado Hernán Vázquez Durán, quien pide una canongía en la iglesia de la Puebla de los Angeles o de México" (11 ene. 1610), AGI, México. 298, f. $1 \mathbf{r}$. 
antiguos puestos no lo quieren hacer". ${ }^{19}$ Aunque otras veces, los pueblos no se vieron beneficiados, en la congregación de Caracuaro, en 1601, "que por la discreción y papeles de su demarcación se coligió tener poca tierra y cogerse maíz, aún para los indios que hay".

Pero la mayor parte de las veces, los indios estaban en franco desacuerdo. muchos se opusieron al programa aduciendo diversas razones. Las más frecuentes eran la diferencia de clima y lo insalubre del lugar seleccionado. Un buen ejemplo de estos argumentos es la opinión de los indios de Cuyotepec que los pretendían reducir en Chachuapa. Señalaban que "el pueblo de Chachuapa es muy enfermo, húmedo y frío que en tiempos de aguas se recoje en él mucha agua llovediza y se hacen ciénegas"."

O como también señalaban los gobernadores de la provincia de los Agualulcos, quienes solicitaron quedarse cada uno en su lugar pero fueron obligados a trasladarse a un nuevo asentamiento.

"parecemos ante vuestra merced por nuestra vejación y por nuestras huertas de cacao y milpas de maíz, y por esto llora nuestro corazón y es muy dificultoso fundar y hacer las huertas de cacao, porque en diez años no da fruto, y por esto estamos con mucha pena por haberlo de dejar". 22

Para garantizar el arraigo forzoso quemaban casas, iglesias y ermitas. $^{23}$ Este hecho provocó que un buen número de indios huyeran a lugares vecinos, como sucedió con los indígenas reducidos en Huayacocotla, quienes "se han ido a vivir en

19 "Informe de méritos y servicio del licenciado Hernán Vázquez Durán, pide una canongía en la iglesia de la Puebla de los Angeles o de México" (11 ene. 1610), AGI, México, 298, f. 1r.

"Informe de los méritos y servicios de Alonso Gutiérrez Calderón, beneficiado del partido de Pongarabato, solicita una ración o media en la iglesia catedral de México o Puebla" (21 abr. 1621), AGI, México, 301, f. 1v.

"2 "Visita y congregación de los pueblos de Nochistlan, San Miguel Huautla, Santa María Chachoapa y San Mateo Coyotepec, hecha por don Francisco de las Casas" (1599-1603), AGNM, Tierras, vol. 1520 , exp. 2, f. 6v.

22 "Estado en que se hallaba la provincia de Coatzacoalcos en el año de 1599" en BAGN, xvi, 239-240.

${ }^{23}$ "Se ha de deshacer algunas iglesias, monasterios y ermitas que hay en los lugares que se despueblan". "Copia de la carta que se escribió a los obispos pidiéndoles por ella su beneplácito para el deshacer de las iglesias de los pueblos que se alzan por la congregación" (5 feb. 1601), AGI, México, 122, ramo 1, núm. 2b, f. 2r., y en "Copia de una carta que se escribió a los religiosos de San Francisco de todos los conventos de ella en razón de la traslación de los ornamentos de las iglesias que se deshacen por la congregación" (17 nov. 1603), AGI, México, 122, ramo 1, núm. 2d. 2 fs. 
términos de los pueblos comarcanos, no se van ni meten en los asientos y lugares de los pueblos fundados y de congregación". ${ }^{24} \mathrm{~A}$ raíz de las congregaciones la articulación que los indígenas tenían con su medio ambiente se fragmentó.

La congregación de pueblos de indios implicó una importante alteración del espacio, se privilegiaron centros, se centralizaron funciones. Las reducciones que se hicieron cerca de los caminos, minas, ventas y mesones provocaron, en un largo proceso, un reordenamiento espacial.

Los movimientos generados, pues, por las congregaciones se insertan en un contexto espacial específico donde los individuos o grupos participaron en la conformación de nuevos rumbos y espacios. Su estudio implica conocer la movilidad dentro y fuera de un área y sus efectos en la distribución espacial.

Las reducciones implicaron, por un lado, movimiento de población, traslado físico de un espacio a otro y, por otro, un reajuste espacial. Se trató de una empresa colectiva. Unas veces el desplazamiento fue de pueblos con una sola identidad étnica y otras el traslado fue de pueblos multiétnicos. La mayoría de las veces fue forzada y compulsiva y en otras voluntaria. No fue espontáneo, sino que estuvo regulado por la administración colonial, aunque en la práctica el proceso rebasó a los proyectos que se fueron implementando. En algunos casos se dieron elementos de migración, es decir, se traspasaron fronteras y jurisdicciones y fueron permanentes.

En párrafos anteriores he insistido en las causas que motivaron los desplazamientos. Ahora me interesa señalar los efectos que ocasionaron los movimientos de población no sólo en el lugar de orígen sino también en el destino. Es notorio el impacto de la movilidad de la población en "la variedad de ambientes sociales, económicos, políticos y ecológicos" (Robinson, 1988, p. 169) y es importante la participación activa, de los que migraron, en el desarrollo y evolución de nuevos centros, como las ciudades y las minas, es decir en la conformación de un nuevo espacio. Sus efectos se proyectaron hacia todos los ámbitos de la sociedad. En resumen, se trata de ver las "huellas" que dejó el movimiento de población.

24 "Relación hecha por don Pedro de Portes de la provincia de Huayacocotla y sus pueblos congregados" (1614), AGNM, Tierras, vol. 2772, exp. 8 f. 2v. 
La movilidad de la población ocasionó en el lugar de procedencia y el de destino cambios y transformaciones. Entre uno y otro punto sería interesante ver el vacío dejado en la población de origen, el volumen de la gente que se desplaza y el aumento de la población en el nuevo asentamiento o lugar de recepción (Sánchez Albornoz, 1982 a, p. 11).

El impacto que causó el desplazamiento de manera inmediata lo podemos encontrar en despoblamiento de ciertos lugares desde fechas muy tempranas, ${ }^{25}$ reflejada a menudo, durante el siglo XVI, en las tasaciones (Miranda, 1980, p. 240-248) y el aumento de la población en otros pueblos. ${ }^{26} \mathrm{~A}$ largo plazo significó la reorganización de la fuerza de trabajo, sobre todo en las labores agrícolas.

De los indígenas que habían servido en el repartimiento, algunos no regresaban a su pueblo y menos aún los que huían. Así muchos indígenas lograron eludir las obligaciones que tenían en sus pueblos; sin embargo, aún hace falta investigar si disfrutaban de la aceptación, bienes y privilegios en el pueblo donde se avecindaban. Los registros parroquiales, los padrones de tributarios y algunos pleitos presentados por el gobernador, alcaldes y regidores de los pueblos hacen mención a la existencia de "barrios de vagabundos", de "vagabundos huidos" y de "forasteros". 27

${ }^{25}$ En la provincia de la Huasteca, en uno de los sujetos de Tlapaguautla, "se despobló este dicho pueblo de Tenesco de miedo de los indios de Cuimatlan, que los enviaba Alonso Ortiz y que se fueron a Tamancho". "Visita que hizo Gómez Nieto, visitador en pueblos de indios a la Huasteca" (1532-1533), AGI, Justicia, 234, f. 795v. En Tanpaca, encomienda de Diego Cortés, "fueles preguntado por qué se había despoblado este dicho pueblo, dijeron que porque Alonso Hernández los encerraba a los principales porque le diesen esclavos y oro y por temor del gallego que los trataba mal", por ello en la cabecera "no había principal ninguno, salvo cuatro o cinco casas de maceguales" y añadieron "que estaban despoblados ciertos pueblos que llama el uno Achaui y Tustla y Tamapache y Puchuo y Tamote [y] Tantlan". "Visita que hizo Gómez Nieto" (15321533), AGI, Justicia, 234, f. 811r.-812r. En Texupexpa, el cacique no se encontró en el momento de la visita, pues se había ido a conseguir alimentos "porque tiene hambre, que no tiene de comer" y añadió que no tenía pueblos sujetos, "ni menos estancias" porque todos se habían ido a Tatelan y a otros pueblos vecinos". "Visita de hizo Gómez Nieto" (1532-1533), AGI, Justicia, 234, 859r.-859v.

Kubler, "Population", 624-628, refiere la recuperación de la población indígena entre 1546 y 1570 en el centro México, Michoacán y Oaxaca debido a la migración indígena de sus áreas periféricas.

Archivo Parroquial de Xochimilco 1592-1600. La tasación del pueblo de La Asunción la Milpa registra 38 indios "vagabundos huídos" para el año de 1598. "Memoria de la población tributaria del pueblo de La Asunción la Milpan" (1598-1602), AGI, México, 121 , ramo 2, núm. 42, f. 32r-32v. Sobre los forasteros, "Información hecha a pedimento 
Uno de los efectos de mayor trascendencia fue la rápida incorporación de la fuerza de trabajo indígena en las empresas de los españoles. Este hecho representó una modificación fundamental. A largo plazo significó un proceso de mestizaje y de aculturación, relacionado con el ciclo de vida, con los valores religiosos, las costumbres, el idioma, la propiedad de la tierra. ${ }^{28}$

Otro de los efectos causados por la movilidad de la población fue el impacto sobre el espacio. Se reordenaron las rutas comerciales a medida que iban creciendo las principales ciudades y se fundaban nuevos centros mineros.

En la doble vertiente que presentan los movimientos de población interesa saber quién o quiénes se desplazaron. Ambos elementos se encuentran recíprocamente relacionados toda vez que las decisiones individuales están afectadas por las decisiones que el grupo pueda tomar. El movimiento, unas veces aislado o individual, se transforma en desplazamiento colectivo con normas, derechos y sanciones. Es selectivo, circular, itinerante, etc., marcado por las oportunidades económicas, sociales y políticas siempre cambiantes.

Una de las formas de desplazamiento individual implicó la tendencia a salir del pueblo. Un buen ejemplo sería el desplazamiento de los mercaderes indígenas hacia los centros mineros, las ciudades y pueblos para abastecerlos de comida e insumos. ${ }^{29}$ Otro, la asignación periódica de trabajadores indígenas de pueblos cercanos y lejanos para las ciudades.

del gobernador, alcaldes, regidores de esta república de Santiago Tecali" (1604), AGNP, Protocolos, paq. 40 , exp. 84 .

28

Durante el siglo XVIII, muchos pueblos alegaron propiedad de las tierras teniendo como punto de partida las reducciones. Por ejemplo, el pueblo de San Francisco Tetlanocan, provincia de Tlaxcala, alegaba "posesión [de sus tierras] de tan dilatado tiempo, que es desde la reducción de los dichos pueblos, y que no ha sido perturbado en manera alguna". "El pueblo de San Francisco alega que siempre ha tenido la exclusividad de sacar resina del monte y que ahora otros pueblos los perturban en ese derecho" (1763), AGET, caja 92, 1750-1751, exp. 24.

29 "Para que los indios de los pueblos comarcanos a las dichas minas de Tasco y de otros cualesquier pueblos lleven maíz, ají, frijoles y los demás bastimentos a quien por bien tuvieren" (1543), AGNM, Mercedes, vol. 2, exp. 480, f. 197r.; "Merced de amparo para que Pedro de Mendoza y otros mercaderes indíos puedan vender sus mercaderías en algunos pueblos sin impedimentos" (1550), AGNM, Mercedes, vol. 3, exp. 599, f. 211v.212r; "Merced a los indios Miguel Tlaylotla, Luis Cocol, Miguel Olin, Martín Zacoa, naturales de la parte de México y Miguel Huicilcalcatl, Pedro Izmollin y Baltazar 
Un elemento siempre presente en la descripción de todo movimiento es el de su unicidad o recurrencia. Se trata de aquellos movimientos que ocurren sóla una vez y los que se repiten en ciclos de días, semanas o meses. La recurrencia y permanencia de un individuo o grupo en un lugar, así como la distribución del tiempo marcada por los ritmos diarios y estacionales son algunas de las variables que surgen aquí. Otro elemento significativo es la distancia. Se debe considerar la cantidad de tiempo invertida en el desplazamiento, ya sea recurrente a un lugar de trabajo o por una vez a un nuevo asentamiento.

Los movimientos pueden ser temporales o permanentes, y entre estos dos parámetros pueden considerarse intervalos de distinta duración y con efectos visibles en la distribución espacial. Los desplazamientos están marcados por el calendario anual y pueden ser diarios, semanales, mensuales, anuales, estacionales, irregulares y permanentes. En esta oportunidad me interesa resaltar algunos de sus rasgos.

Las labores diarias que implican el traslado para el acarreo de agua, el trabajo en la milpa familiar, el pastoreo, etc., constituyen desplazamientos cotidianos. En nuestro caso particular estos movimientos se suceden unas veces dentro del pueblo pero en otras se requiere del cruzamiento de sus fronteras, sobre todo cuando se trata del abasto a las ciudades. ${ }^{30}$ Este tipo de desplazamiento la mayoría de las veces fue individual. Muchas de estas actividades a lo largo del proceso colonial fueron transformadas, sobre todo a raíz del proceso de congregaciones o reducciones, lo que implicó verdaderos cambios en la vida de los pueblos indios.

Las levas periódicas de trabajadores dirigidas hacia la agricultura, las minas y las ciudades, y cuya permanencia era de más de dos días, a corta o larga distancia, constituía otro tipo de desplazamiento. Estas asignaciones eran regulares también para otros sectores como los obrajes, el corte de madera y el abasto a la ciudad, o eran estacionales como resultado del calendario agrícola,

Cuscatecat, naturales de la parte de Santiago puedan vender mantas de algodón en los tianguiz de la ciudad de México, como en las minas y otras parte de esta Nueva España" (1551), AGNM, Mercedes, vol. 3, exp. 649, f. 257v.-258r.

El abasto a la ciudad estuvo garantizado por las redes comerciales que los indígenas tenían establecidas desde la época prehispánica. Durante el siglo XVI diversos mandamientos dados en favor de los indios de Churubusco, Cuernavaca, México y Santiago garantizaron el abasto cotidiano a la ciudad de México. AGNM, Mercedes, vol. 3, exp. 716 , f. 277 v. -278 v., vol. 3, exp. 730 , f. 285 r.-285v., vol. 3, exp. 731 , f. 285 v.-286r., vol. 3 , exp. 881 , f. 345 r. -346 r. 
que implicaba que muchos pueblos se desprendieran anualmente de fuerza de trabajo sobre todo para las labores agrícolas. Esta coyuntura influye en la manera que debían elegir para contribuir al repartimiento. Una característica que podría ser significativa de esta movilidad es la participación del cabildo que regulaba las idas y vueltas en el calendario anual.

La migración es otro tipo de movimiento. Implica el cruzamiento de una frontera civil o eclesiástica, es un desplazamiento único, no recurrente, como sucedió con los migrantes tarascos, mexicanos, tlaxcaltecas, cholultecas y huexotzincas en el norte.

"Por cuanto Alonso de Espino, clérigo presbítero beneficiado de la villa de León, me ha hecho relación que a tiempo de siete años que éste vive y reside en la dicha villa donde ha procurado con toda diligencia y cuidado aumentar la población con indios tarascos y mexicanos, que voluntariamente han querido venirse a poblar allí, de que resultan muchos provechos y utilidad grande a la conservación de la dicha villa"."31

Las unidades espaciales tienen límites, jurisdicciones y fronteras, por lo que interesa ver el tamaño y la morfología de estas unidades. Es decir, se hace necesario definir las unidades tanto de orden eclesiástico como político, cultural o de otro tipo, su tamaño y el tiempo de permanencia en el nuevo asentamiento de aquél o de aquéllos que salen de sus pueblos. La unidad espacial más relevante en será, pues, el pueblo o altepetl en el sentido de una "colectividad integrada jurídicamente" (García Martínez, 1987, p. 78) que posee una identidad, una tradición, un territorio y una estructura; esta unidad se integra a otra más amplia: la región. ${ }^{32}$ Unas veces el indígena se trasladaba a otro barrio, o parroquia y, en otras, recorría distancias considerables y cruzaba entornos ajenos, lo que implicaba el traslado de y hacia

31 "Para que ninguna justicia, ni persona impidan a los indios que quisieren ir a vivir a la villa de León, ir a ella a poblarla pagando al pueblo de donde saliere el tributo de un año por entero" (1582), AGNM, Indios, vol 2, exp. 155, f.39v.; "Para que el alcalde mayor de la villa de Celaya, dentro de ella, señalase solares a los indios que en la dicha villa se avecindasen, de nación mexicana, tlaxcalteca, cholulteca, huexotzinca y les guardase las mismas preeminencias que a los vecinos españoles". "Mandamiento para que se diere solares a los indios" (29 ago. 1591). AGNM, Indios, vol. 3, exp. 936, f. 227v.-228r.

32 "Entiendo por región a un espacio articulado sobre la base de un conjunto funcional de relaciones espaciales y percibido como individual y discreto por quienes participan en ellas. Entendida así, una región es un espacio cambiante y determinado por la cultura, y por lo mismo histórico, ligado desde luego al medio físico pero no definido por él". García Martínez, Los pueblos, 24-25. 
jurisdicciones mayores, como serían otros pueblos de indios, alcaldías mayores o corregimientos y obispados.

Aún cuando la referencia a un pueblo cubre distintas extensiones, los límites administrativos y jurisdiccionales se modificaron y muchas veces las fronteras eclesiásticas y políticas se sobreponían y no coincidían. Por lo mismo, para entender las migraciones es importante señalar la ubicación de los pueblos, sobre todo los que estaban ligados a las rutas comerciales, a los centros mineros y agrícolas.

Un movimiento de población comprende dos extremos: el lugar de orígen y el de destino. Entre ambos se sitúan todos los movimientos de población. Se da el caso de que algunos desplazamientos tengan como punto de partida y llegada un mismo lugar.

Los desplazamientos ocurren dentro de un mismo sistema ecológico o fuera de él con el fin de conseguir recursos, pues no todos los pueblos indios producían todos los productos que les eran necesarios y para su subsistencia debían recurrir a un conjunto de productos que se producían fuera de su territorio.

Los desplazamientos ocurren dentro o fuera de una estructura espacial articulada. Interesa señalar el papel que jugó en un momento dado una ciudad, una red de unidades productivas, debido a la atracción que representó el cada vez más creciente mercado colonial y el surgimiento de polos de desarrollo (Cook, 1976; Sánchez-Albornoz, "Migración urbana", 1982b, 1988; Charney, 1988). Pero conviene destacar que las ciudades no fueron necesariamente el eje principal de esta dinámica. Los flujos de movimiento hacia adentro o fuera de una región sugieren estudiar las rutas comerciales.

Los movimientos se suceden dentro de un mismo territorio o dentro de un pueblo, o bien hacia otros pueblos o territorios (Sánchez-Albornoz, 1983a, 1982a; Miranda, 1962). Se trata de pueblos entralazados en los circuitos del movimiento de población. En este sentido las congregaciones implicaron el desplazamiento de la población casi siempre dentro de un mismo pueblo, pero a veces de uno a otro.

El análisis sobre la movilidad de la población debe hacerse sin dejar de lado aspectos importantes como la cuestión étnica. Una característica de las congregaciones es que a veces implicaron el desplazamiento de pueblos multiétnicos con diversas identidades culturales en un solo asentamiento. En el pueblo de Ixtlahuaca se congregaron indígenas que hablaban "las lenguas mexicanas, mazagua y otomí", en el pueblo de Huayacocotla se 
congregaron otomis y mexicanos. ${ }^{33} \mathrm{Al}$ concentrarse a la población dispera en nuevos centros, grupos étnicos distintos se mezclaron. Es probable que la fusión de etnias distintas haya provocado la "pérdida sucesiva de su identidad" y haya propiciado la emergencia del indio, como una verdadera creación colonial.

Por último, cabe señalar que aún hace falta un estudio a profundidad de los desplazamientos de la población, del impacto sobre el espacio y de su importancia no sólo para la la historia de la población sino para el historia en general.

\section{Siglas}

AGI Archivo General de Indias, Sevilla.

AGNM Archivo General de la Nación, México, D. F.

AGNot Archivo General de Notarías, México, D. F.

AGNP Archivo General de Notarías, Puebla.

AGET Archivo General del Estado de Tlaxcala.

CDIAO Colección de documentos inéditos...

\section{Referências bibliográficas}

ASSADOURIAN, Carlos Sempat [1989]. La despoblación indígena en Perú y Nueva España durante el siglo XVI y la formación de la economía colonial. Historia mexicana, XXXVIII, 3 [151] (ene.), p. 419-453.

BOEHM de LAMEIRAS, Brigitte [1986]. Formación del estado en el México prehispánico. Zamora: El Colegio de Michoacán.

BOYD-BOWMAN, Peter [1963]. La emigración peninsular en América (1520-1539). Historia mexicana, XIII, 2 [50] (oct.), p. 165-192.

BOYD-BOWMAN, Peter [1974]. Patterns of spanish emigration to the Indies (15791600). The Americas, 33:1 (jul.), p. 24-35.

BOYD-BOWMAN, Peter [1976]. Patterns of spanish emigration to the Indies until 1600. Hispanic American Historical Review, 56, 4 (nov.), p. 580-604.

CERVANTES de SALAZAR, Francisco [1975]. Crónica de la Nueva España (1514-1575). México: Editorial Porrúa [Biblioteca Porrúa, 84].

CDIAO [1964-66]. Colección de documentos inéditos relativos al descubrimiento, conquista y colonización de las posesiones españolas en América y Oceanía, sacadas en su mayor parte del Real Archivo de Indias [editado por Joaquín F. Pacheco, Francisco de Cárdenas y Luis Torres de Mendoza]. Madrid, 1864-1884, 42 vols (Facsímil: Vaduz, Nendeln).

Códice Aubin [1892]. Códice Aubin ou de 1576: Histoire de la nation mexicaine depuis le depart d'Aztlan jusqu'a l'arrivée des conquérants espagnols (et au dela de 1607) [réproduction du Codex de 1576 appartenant a la collection de M. E. Eugene Goupil, ancienne collection Aubin]. Paris: Maison Neuve Freres Editeurs [Librairie Orientale et Américaine].

Códice Ramírez [1975]. "Códice Ramírez", Hernando Alvarado Tezozomoc. Crónica Mexicana. México: Editorial Porrúa.

33 "Proceso de la junta y congregación del pueblo de Ixtlahuaca" (1593), AGNM, Tierras, vol. 1595, exp. 8, cuaderno 1,f. 2v. "Proceso de la junta y congregación del pueblo de Jiquipilco" (1593), AGNM, Tierras, vol 1595, exp. 8, cuaderno 2, f. 5v. "Relación hecha por don Pedro de Portes de la provincia de Huayacocotla”(1614), AGNM, Tierras, vol. 2772, exp. 8. f. $14 v$. 
Codice Xolotl [1976]. "Códice Xolotl". In: Memoria de las obras del sistema de drenaje profundo del Distrito Federal. México: Departamento del Distrito Federal, vol. V.

COOK, Noble D. [1976]. Les indiens inmigrés à Lima au debut du XVIIe siècle. Cahiers des Ameriques Latines, 13-14, p. 35-50.

COOK, Sherburne F. [1970]. Las migraciones en la historia de la población mexicana: Datos modelo del occidente del centro de México (1793-1950). In: GARCIA, Bernardo et al (eds.). Historia y sociedad en el mundo de habla española: Homenaje a José Miranda. México: El Colegio de México, p. 355-377.

CLINE, Howard [1949]. The Civil Congregations of the Indians of New Spain (15981608). The Hispanic American_Historical Review, 29, 3 (ago.), p. 349-369.

CHARNEY, Paul J. [1988]. El indio urbano: un análisis económico y social de la población india de Lima en 1613. Histórica, XII, 1, (jul.), p. 5-33.

DÍAZ del CASTILLO, Bernal [1976]. Historia verdadera de la conquista de la Nueva España. México: Editorial Porrúa [Sepan cuantos, 5].

DURÁN, Diego [1967]. Historia de las Indias de la Nueva España e Islas de la Tierra Firme. México: Editorial Porrúa, 2 vols. [Biblioteca Porrúa, 36-37].

DEL HOYO, Eugenio [1979]. Historia del Nuevo Reino de León (1577-1723). Monterrey: Editorial Al Voleo.

Epistolario [1939-42]. Epistolario de Nueva España [editado por Francisco del Paso y Troncoso]. México: Antigua Librería Robredo de José Porrúa e Hijos, 16 vols. [Biblioteca histórica mexicana de obras inéditas, 2da. Serie].

Estado de la provincia de Coatzacoalcos (1599) [1945]. Estado en que se halla la provincia de Coatzacoalcos en el año de 1599. Boletín del Archivo General de la Nación, XVI, 2-3: p. 197-246 e p. 429-497.

FARRIS, Nancy M. [1978]. Nucletion versus dispersal: The dynamics of population movement in colonial Yucatan. Hispanic American Historical Review, 58, 2 (may.), p. 187-216.

FARRIS, Nancy M. [1984]. Maya society under spanish rule: The collective enterprise of survival. Princeton: Princeton University Press.

FERNÁNDEZ TEJEDO, Isabel y François Gresteau [1986]. La movilidad de la población rural yucateca (1548-1642). Historias, 13, p. 27-39.

FLORESCANO, Enrique [1973]. Colonización, ocupación del suelo y "frontera" en el norte de Nueva España (1521-1750). In: FLORESCA, Enrique et al (eds.). Tierras nuevas: Expansión territorial y ocupación del suelo en América (siglos XVI-XIX). México: El Colegio de México [Centro de Estudios Históricos. Nueva serie, 7], p. 43-76.

FLORESCANO, Enrique [1987]. Memoria mexicana: Ensayo sobre la reconstrucción del pasado (época prehispánica-1821). México: Joaquín Mortiz-Contrapuntos.

GARCÍA MARTÍNEZ, Bernardo [1987]. Los pueblos de la sierra: El poder y el espacio entre los indios del norte de Puebla hasta 1700. México: El Colegio de México.

GIBSON, Charles [1980]. Los aztecas bajo el dominio español (1519-1810). México: Siglo XXI [Colección América nuestra, 15].

Historia Tolteca Chichimeca [1976]. [Editado por Paul KIRCHHOFF, Lina Odena GÜEMES y Luis Reyes GARCÍA]. México: Centro de Investigaciones Superiores del Instituto Nacional de Antropología e Historia.

IXTLILXÓCHTL, Fernando de Alva [1975]. Obras históricas [editadas por Edmundo O'Gorman]. México: Instituto de Investigaciones Históricas/Universidad Nacional Autónoma de México, 2 vols. [Historiadores y cronistas de Indias, 2].

KUBLER, George [1942]. Population movements in Mexico (1520-1600). Hispanic American Historical Review, XX, 2 (nov.), p. 606-643.

LECOIN, Sylvie [1988]. Intercambios, movimientos de población y trabajo en la diócesis de Michoacán en el siglo XVI (un aspecto de las Relaciones Geográficas de 1580). In: CALVO, Thomas \& LÓPEZ, Gustavo (eds.). Movimientos de población en el Occidente de México. Zamora: El Colegio de Michoacán/Centre d'Etudes Mexicaines et Centroamericaines, p. 123-137.

LICATE, Jack [1981]. Creation of A Mexican Landscape: Territorial Organization and Settlement in the Eastern Puebla Basin (1520-1605). Chicago: University of Chicago [Department of Geography: Research Papers, 201]. 
LÓPEZ AUSTIN, Alfredo [1973]. Hombre-Dios: Religión y política en el mundo náhuatl. México: Universidad Nacional Autónoma de México [Instituto de Investigaciones Históricas: Serie de cultura náhuatl, monografías, 13].

Mandamientos [1960]. Mandamientos del virrey conde de Monterrey para la congregación de pueblos de indios en la alcaldía mayor de Valladolid [editados por Ernesto Lemoine V.]. Boletín del Archivo General de la Nación, I, 1, p. 9-55.

MARTIN, Norman F. [1957]. Los vagabundos en la Nueva España siglo XVI. México: Editorial Jus.

MARTÍNEZ MARÍN, Carlos [1972]. La cultura de los mexicas durante la migración. In: PORTILLA, Miguel León (ed.). De Teotihuacan a los aztecas, fuentes e interpretación históricas. México: Universidad Nacional Autónoma de México [Lecturas universitarias, 2], p. 247-255.

MARTÍNEZ MARÍN, Carlos [1977]. Historiografía de la migración mexica. Estudios de cultura nahuatl, XII, p. 121-135.

MIRANDA, José [1962a]. La pax hispánica y los desplazamientos de los pueblos indígenas. Cuadernos americanos, XXI, 26 [125] (nov.), p. 186-198.

MIRANDA, José [1962b]. La población indígena de México en el siglo XVII. Historia mexicana, XII, 2 [46] (oct.), p. 182-189.

MIRANDA, José [1968]. Evolución cuantitativa y desplazamiento de la población indígena de Oaxaca en la época colonial. Estudios de historia novohispana, II, p. 129148.

MIRANDA, José [1980]. El tributo indígena en la Nueva España durante el siglo XVI. México: El Colegio de México [Centro de Estudios Históricos. Nueva serie, 32].

Moderación de doctrinas [1959]. Moderación de doctrinas de la real corona administradas por las órdenes mendicantes (1623) [editada por France V. SCHOLES \& Eleanor B. ADAMS]. México: José Porrúa e Hijos [Documentos para la historia del México Colonial, 6].

PERCHERON, Nicole [1988]. Colonización española y despoblación de las comunidades indígenas: La catástrofe demográfica entre los indios de Michoacán en el siglo XVI, según las Relaciones Geográficas de las Indias (1579-1582). In: CALVO, Thomas \& LÓPEZ, Gustavo (eds.). Movimientos de población en el Occidente de México. Zamora: El Colegio de Michoacán/Centre d'Etudes Mexicaines et Centroamericaines, p. 139-166.

POWELL, Philip W. [1977]. La guerra chichimeca (1550-1600). México: Fondo de Cultura Económica [Sección obras de historia].

PRIEN, Hans-Jürgen [1978]. Milpa y hacienda: Tenencia de la tierra indígena y española en la cuenca del Alto Atoyac. Puebla, México (1520-1650) [con contribuciones de Ursula Dyckerhoff y Günter Miehlich]. Wiesbadaen: Steiner Verlag [El proyecto México de la fundación alemana para la investigación científica, 13].

Protesta de los indios [1960]. Protesta de los indios de Atoyac para no ser congregados en el pueblo de Tecpan (año de 1614) [editado por Ernesto LEMOINE ]. Boletín del Archivo General de la Nación, I, 4, p. 535-549.

RABELL, Cecilia [1986]. Los diezmos de San Luis de la Paz: Economía en una región del Bajío en el siglo XVIII. México: Universidad Nacional Autónoma de México.

REYES GARCÍA, Luis [1959]. Movimientos demográficos en la población indígena de Chiapas durante la época colonial [Sociedad Mexicana de Antropología], p. 25-48.

ROBINSON, David J. [1981]. Indian migration in eighteenth-century Yucatán: The open nature of the closed corporate community. In: ROBINSON, David J. (ed.). Studies in Spanish American population history. Boulder/Colorado: Westview Press [Delleplain Latin American Studies, 8], p. 149-173.

ROBINSON, David J. [1988]. Patrones de migración en Michoacán en el siglo XVIII: Datos y metodologías. In: CALVO, Thomas \& LÓPEZ, Gustavo (eds.). Movimientos de población en el Occidente de México. Zamora: El Colegio de Michoacán/Centre d'Etudes Mexicaines et Centroamericaines, p. 169-205.

ROBINSON, David J. \& CAROLYN G. McGovern [1980]. La migración regional yucateca en la época colonial: El caso de San Francisco de Umán. Historia mexicana, XXX, 1 [117] (jul.), p. 90-125. 
SÁNCHEZ-ALBORNOZ, Nicolás [1978]. Indios y tributos en el Alto Perú. Lima: Instituto de Estudios Peruanos [Historia andina, 6].

SÁNCHEZ-ALBORNOZ, Nicolás [1982a]. Migraciones internas en el alto Perú: El saldo acumulado en 1646. Historia boliviana, 2, 1, p. 11-19.

SÁNCHES-ALBORNOZ, Nicolás [1982b]. Migración urbana y trabajo: Los indios de Arequipa (1571-1645). In: De historia e historiadores: Homenaje a José Luis Romero. México: Siglo XXI, p. 259-281.

SÁNCHES-ALBORNOZ, Nicolás [1983a] Migración rural en los andes, Sipesipe (Cochabamba), (1645). Revista de historia económica, I, 1,p. 13-36.

SÁNCHES-ALBORNOZ, Nicolás [1983b]. Mita, migración y pueblos: Variaciones en el espacio y en el tiempo. Alto Perú (1573-1652). Historia boliviana, III,1, p. 31-56.

SÁNCHES-ALBORNOZ, Nicolás [1988]. La mita de Lima: Magnitud y procedencia. Histórica, XII, 2, (dic.), p. 193-205.

VAN ZANTWIJK, R. [1972]. La organización de once guarniciones aztecas. Una nueva interpretación de los folios 17v. y 18r. del Códice Mendocino. Cahiers des Ameriques Latines, 49, p. 149-160.

VELÁZQUEZ, Primo Feliciano [1946-1948]Historia de San Luis Potosí, 4 vols. México, 1946-1948.

ZAVALA, Silvio [1952]. Nuño de Guzmán y la esclavitud de los indios. Historia mexicana, I, 3 [3] (ene.), p. 411-428.

ZAVALA, Silvio [1981]. Los esclavos indios en Nueva España. México: El Colegio Nacional.

ZAVALA, Silvio [1984]. La libertad de movimiento de los indios de Nueva España. Estudios indianos, México: El Colegio Nacional, p. 355-431. 